administration (52\%), followed by prescription (30\%) and transcription of medications (12\%). Most commonly involved medications in MEs were anti-pyretics (33\%), those for respiratory conditions $(15 \%)$ and analgesics (13\%). Of the MEs, 9 (9\%) were serious errors requiring enhanced monitoring and/ or intervention, while $1(1 \%)$ caused temporary patient harm. Human factors (92\%) was the most frequently documented contributing factor, namely failure to comply with established workflows, accurate information provided by guardians, and distractions.

Conclusions We have described a low incidence of MEs from 2013 to 2019. Strategies should be developed to ameliorate MEs in the pediatric ED. Areas for focused intervention should include systematic evaluation of drug administration and prescription processes, to enhance compliance with established procedures of checking (amongst the healthcare team and with guardians) and putting safeguards in place to minimize the impact of distractions in the ED setting.

\section{PROMOTING EARLY INTERVENTION FOR SPECIAL- NEEDS CHILDREN AS A BRANCH SERVICE OF PEDIATRIC NEUROLOGY}

Pyae Phyo Aung, Nay Linn, Kyaw Linn, Aye-Mya Min-Aye, Ayemu Saan, Nway Nway. Myanmar

\subsection{6/bmjpo-2021-RCPCH.214}

Background Since the establishment of pediatric neurology services in 2011, pediatric neurology team has been dealing with increasing numbers of different neurological problems year by year. Developmental, speech and language and behavioral problems are quite common in out-patient clinics. In 2017, UNICEF estimated that $42 \%$ to $45 \%$ of young Myanmar children need early childhood intervention services. So Child Development Center (CDC) was launched in 2017 as a branch of Pediatric Neurology with services such as developmental screening, assessment and appropriate intervention.

Objectives The objective of the study is to evaluate early intervention services for children who were enrolled in CDC.

Methods Retrospective study was done on early intervention services in CDC through the review of CDC registration records from 2017 to 2020. The study population included all the children referred for screening, assessment and interventions. After enrollment, thorough history, and relevant general, systemic as well as neurological examinations and necessary investigations were performed for diagnosis and underlying causes. Pediatric neurologists also conducted developmental screening and necessary neurodevelopmental assessments by using instruments such as Schedule of Growing Skills-2, Conner Rating Scale and DSM-5 Diagnostic Criteria. Then, appropriate interventions such as physiotherapy, occupational, speech, behavior and self-care therapies were given by allied professionals in voluntary participation and paraprofessionals. The extracted data from CDC registry to analyze were demographic variables, presenting symptoms, medical history and examination findings, results of developmental assessment and diagnoses and therapy services.

Results A total of 138 children with girls (30.43\%) and boys $(69.57 \%)$ were enrolled. The youngest age at enrollment was 1 year, the oldest 15 year with a mean age of 4.558 year. The most common developmental problems were global developmental delay (GDD) (54.35\%), autism spectrum disorder

\begin{tabular}{|c|c|c|c|c|}
\hline \multirow{2}{*}{$\begin{array}{l}\text { Demographic } \\
\text { characteristics }\end{array}$} & \multicolumn{4}{|c|}{ Total $\mathrm{N}=138$} \\
\hline & $n$ & $\%$ & Mean & SD \\
\hline Gender & 42 & 30.43 & & \\
\hline Female & 96 & 69.57 & & \\
\hline \multicolumn{5}{|l|}{ Male } \\
\hline Age (Year) at enrollment & & & 4.558 & 2.628 \\
\hline \multicolumn{5}{|l|}{ **minimum age is 1 year } \\
\hline Age (Year) & & 72.46 & & \\
\hline $0-5$ & 100 & 22.46 & & \\
\hline $6-10$ & 31 & 5.07 & & \\
\hline $11-15$ & 7 & & & \\
\hline Age (Year) of GDD & & & 3.259 & 1.231 \\
\hline \multicolumn{5}{|l|}{ diagnosis } \\
\hline \multicolumn{5}{|l|}{${ }^{* *}$ minimum age is 1 year } \\
\hline Age (Year) of ASD & & & 3.75 & 1.939 \\
\hline \multicolumn{5}{|l|}{ diagnosis } \\
\hline \multicolumn{5}{|l|}{${ }^{* *}$ minimum age is 2 years } \\
\hline 2017 Assessment & 23 & 16.67 & & \\
\hline 2018 Assessment & 51 & 36.96 & & \\
\hline 2019 Assessment & 51 & 36.96 & & \\
\hline 2020 Assessment & 13 & 9.42 & & \\
\hline
\end{tabular}

(ASD) (17.39\%) and speech and language delay (SLD) (16.67\%) with male-predominance in GDD (64.81\%), ASD $(79.17 \%)$ and SLD (78.26\%) respectively. Speech problems (97.62\%), language (97.5\%) and adaptive skills (93.33\%) delay and behavior problems (37.93\%) were the most common presentation in GDD. Youngest age for ASD by DSM-5 was 2 years with a mean age of 3.75 years. Problem-in-makingfriends (75\%), poor-eye-contact $(70.83 \%)$, stereotypies $(54.17 \%)$ and odd-play (41.67\%) were the most encountered autism symptoms in children with ASD. Rising trend was found in assessment (36.96\% in both 2018 and 2019) and therapy services in comparison with 2017.

Conclusions This study explores the promotion of early intervention services for special-needs children as part of pediatric neurology. Scaling up better holistic intervention services in multidisciplinary approach and the study aiming for the outcome of children benefiting from CDC services are further considerations against impact of COVID-19 pandemic in 2020 .

\section{CAPTURING THE RESPONSE TO THE COVID-19 PANDEMIC IN A UK DISTRICT GENERAL HOSPITAL PAEDIATRIC DEPARTMENT}

Felicity Cooksey, Anna Cripps, Gita Modgil. UK

\subsection{6/bmjpo-2021-RCPCH.215}

Background In response to the coronavirus pandemic, the paediatric team have needed to make rapid changes to our pathways and ways of working. In this time colleagues have fast tracked the testing of new processes and generated ideas to deliver continuous improvement.

Objectives General objective: To capture the rapid changes made to healthcare practices within the Paediatric department at Musgrove Park Hospital, Taunton in response to the coronavirus pandemic and to share learning across the directorate. 